NASZA DERMATOLOGIA Online OUR DERMATOLOGY Online

of Support:

Nil

Competing Interests:

None

\section{RECALCITRANT WIDESPREAD ALOPECIA AREATA IN A CHILD TREATED SUCCESSFULLY WITH ORAL METHYLPREDNISOLONE PULSE THERAPY}

\author{
Neerja Puri
}

Department of Dermatology GGS Medical College, Faridkot, 151203, India

Corresponding author: Dr. Neerja Puri

neerjaashu@,rediffmail.com

\begin{abstract}
Alopecia areata is a common condition with patchy non scarring hair loss. We report a case of an 11 year old male child with localized patch of hair loss on the frontoparietal region of the scalp since one year. It was a widespread extensive patch of hair loss covering more than $40 \%$ of the scalp. On hair shaft microscopy, numerous exclamation mark hairs were present. The patient was put on topical tacrolimus and topical corticosteroids but no response was seen. Since the child was recalcitrant to treatment, methylprednisolone $500 \mathrm{mg} /$ day on three consecutive days in a month was given. After six months $80 \%$ regrowth was seen over the affected area of the scalp.
\end{abstract}

Key words: hair; scalp; alopecia; corticosteroids; treatment; topical

\section{Introduction}

Alopecia areata (AA) is a relatively common patchy nonscarring hair loss condition. The annual incidence rate is 20 . 2 per 100,000 and the lifetime risk is estimated at $1.7 \%$ [1]. Although most small AA lesions resolve spontaneously, 14$25 \%$ of AA patients referred to secondary and tertiary centers progress to total loss of scalp hair or to loss of all scalp and body hair, from which full recovery is unusual $[2,3]$.

In the widespread cases in which the remaining hair cannot cover the alopecic sites, there can be tremendous psychological stress. Experimental studies have reported that the pathogenesis of AA is an autoimmune assault on hair follicles [4]. Since the 1950 s, oral administration of corticosteroid therapy has been the treatment of choice for recalcitrant AA [5]. However, prolonged use of corticosteroids is limited because of adverse side effects and recurrence after discontinuation. Pulse corticosteroid therapy has also been used to control the active phase of hair loss of AA. According to the recent reports, the dosage of pulse corticosteroids commonly used in treating AA is $500 \mathrm{mg} /$ day or 8 $\mathrm{mg} / \mathrm{kg} /$ day of intravenous methylprednisolone for 3 consecutive days $[6,7]$. Lower dosage of oral prednisolone is also used in other studies $[8,9]$. Severe side effects were not described in those reports. Although acute phases of hair loss are followed by spontaneous hair regrowth in most patients, the disorder may persist for many years or even for life when severe. But even in these cases hair loss is potentially reversible, because the disease usually does not result in destruction of hair follicles or scarring. In consideration of the TH-1 mediated immune attack on the hair follicle in AA, corticosteroids are potentially good candidates for the treatment of this disease.

Topical, intralesional and systemic corticosteroids have been used to treat AA, with different rates of success and sideeffects. The failure of topical corticosteroids is most likely due to the insufficient penetration of topically applied drugs from ointments, creams or lotions into the hair bulb. Improving penetration by occlusion has been tried without success.

\section{Case Report}

An 11 year old male child reported to the department of dermatology with localized patch of hair loss on the frontoparietal region of the scalp since one year. It was a widespread extensive patch of hair loss covering more than $40 \%$ of the scalp. On local examination, the patch of hair loss measured $4 \mathrm{~cm} \times 5 \mathrm{~cm}$ in size (Fig. 1). The scalp was not tender or bruised and there was no evidence of scarring. On hair shaft microscopy,numerous exclamation mark hairs were present. A pottasium hydroxide preparation from the lesional skin did not show any fungal elements. The child had positive family history and history of atopy was also positive. Complete blood cell count, serum chemistry, chest X-ray, electrocardiogram, thyroid function test and antinuclear antigen were checked before starting the pulse corticosteroid therapy.

The patient was put on topical tacrolimus for 8 weeks, but no response was seen. Later, the patient was put on topical corticosteroids for 8-10 weeks without any re growth of hair. Since the child was recalcitrant to treatment, methylprednisolone $500 \mathrm{mg} /$ day on three consecutive days in a month was given. 
The steroid pulses were given for three months and the response was seen in six months (Fig. 2). No serious adverse effects were recorded except for transient giddiness, hedadache and epigastric burning. Evaluation of the hair regrowth was made by photo of the patient 6 months after the pulse therapy. Hair growth was

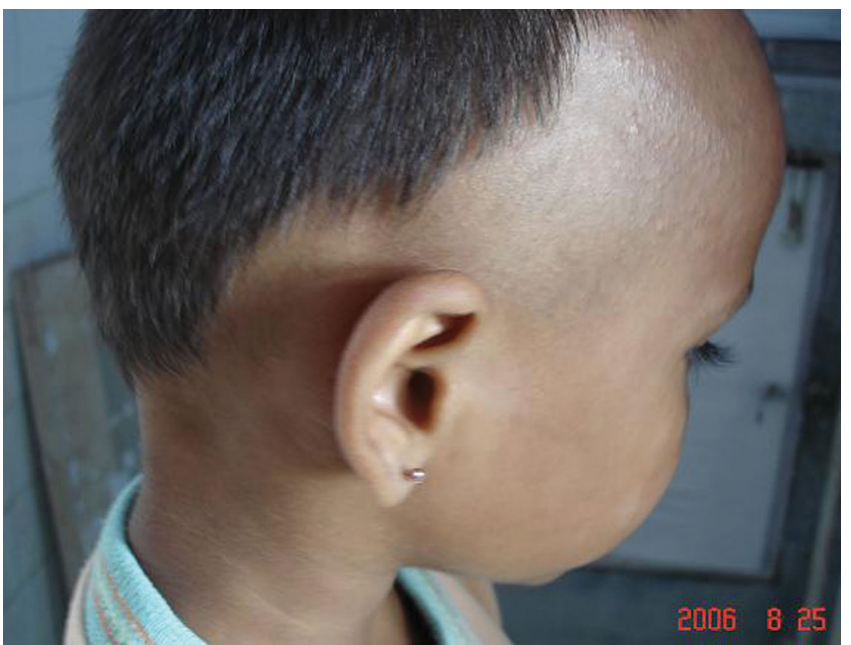

Figure 1. An 11 year old child with patchy alopecia

\section{Discussion}

It has been hypothesized that the advantage of pulse therapy compared to regular administration of corticosteroid is due not only to fully ligand-occupied glucocorticoid receptors but also to nongenomic actions, including membrane-bound glucocorticoid - receptor - mediated signaling and direct physicochemical actions on the plasma membrane, which lead to the dysfunction of immune cells [10]. High corticosteroid levels attained during the therapy may help correct the cytokine imbalance systemically or restore the immune privilege locally. Previous studies indicate that good responders to pulse corticosteroid therapy tend to have recent-onset hair loss of plurifocal lesions and that poor responders have alopecia totalis/universalis or ophiasic lesion [11,12]. The dosage of corticosteroid administered in this study was $500 \mathrm{mg}$ /day methylprednisolone on 3 consecutive days. Whereas, initially, oral corticosteroids were used daily or every other day for several months, this continuous use of corticosteroids is obsolete today. Doses that are required to maintain hair regrowth in AA are between 30 and $150 \mathrm{mg}$ daily, giving rise to unacceptable side-effects such as hypertension, diabetes, immunosuppression, osteoporosis and proneness to thrombosis. It is yet to be determined whether pulse corticosteroid therapy during early stages of severe AA will be able to change the long-term prognosis.

Several immunosuppressive agents have also been used for recalcitrant AA patients. Although cyclosporine has been applied for severe AA patients, the efficacy may not be satisfactory because of resistant cases, recurrence after discontinuation and adverse side effects, including hypertension and gingival hyperplasia $[13,14]$. According to a recent report, methotrexate alone or in combination with low doses of corticosteroids was effective in severe long-term AA [15]. Alefacept, which is a lymphocyte-function-associated antigen $3 / \operatorname{IgG}$ fusion protein that blocks $\mathrm{T}$ cell activation, has also been used for recalcitrant assessed on a percentage scale ranging from 0 to $100 \%$. Only growth of terminal hair, not vellus hair from the lesions was regarded as regrowth. After six months $80 \%$ regrowth was seen over the affected area of the scalp.

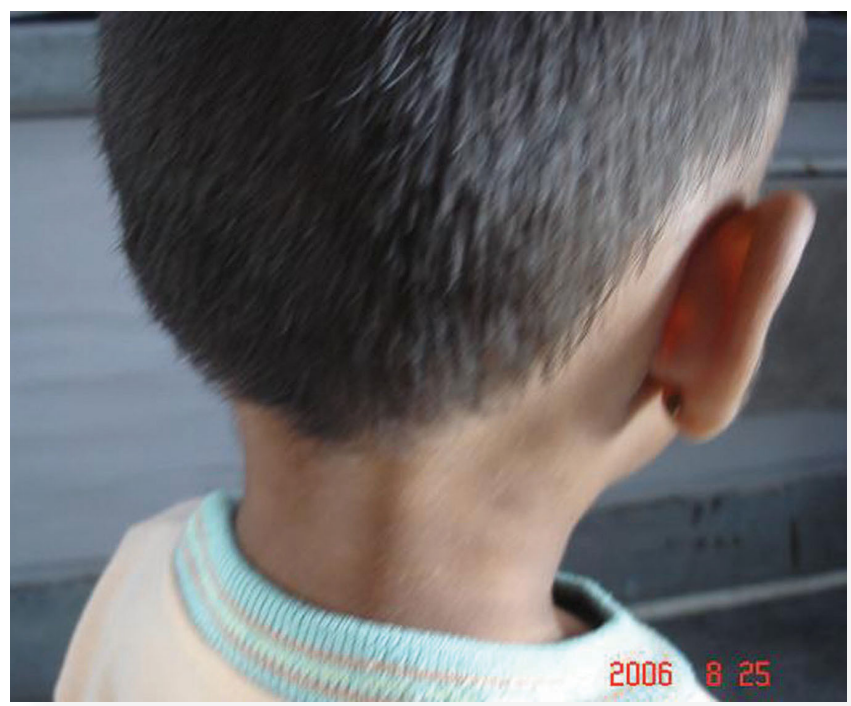

Figure 2. After 6 months of treatment

AA and has achieved some degree of improvement [16].

\section{Conclusion}

Since 1975 several authors have performed pulsed administration of corticosteroids in single doses, given once monthly in order to reduce the side-effects of corticosteroids to an acceptable level, but all studies which noted hair regrowth, were uncontrolled and the majority of patients had patchy AA. Moreover, other studies reported treatment failure after corticosteroid pulse therapy. Controlled studies should be conducted to prove the efficacy and long-term value of this treatment. Especially the efficacy in interrupting acute phases of rapid hair loss by pulsed administration of oral corticosteroids should be investigated.

\section{REFERENCES}

1. Safavi KH, Muller SA, Suman VJ, Moshell AN, Melton LJ 3rd: Incidence of alopecia areata in Olmsted County, Minnesota, 1975 through 1989. Mayo Clin Proc. 1995;70:628-33.

2. Tosti A, De Padova MP, Minghetti G, Veronesi S: Therapies versus placebo in the treatment of patchy alopecia areata. J Am Acad Dermatol. 1986;15:209-10.

3. MacDonald Hull SP, Wood ML, Hutchinson PE, Sladden M, Messenger AG: Guidelines for the management of alopecia areata. Br J Dermatol. 2003;149:692-9.

4. Gilhar A, Kam Y, Assy B, Kalish RS: Alopecia areata induced in $\mathrm{C} 3 \mathrm{H} / \mathrm{HeJ}$ mice by interferon-gamma: evidence for loss of immune privilege. J Invest Dermatol. 2005;124:288-9.

5. Dillaha CJ, Rothman S: Therapeutic experiments in alopecia areata with orally administered cortisone. J Am Med Assoc. 1952;150:54650 .

6. Perriard-Wolfensberger J, Pasche-Koo F, Mainetti C, Labarthe MP, Salomon D, Saurat JH: Pulse of methylprednisolone in alopecia areata. Dermatology: 1993;187:282-5. 
7. Friedli A, Labarthe MP, Engelhardt E, Feldmann R, Salomon D, Saurat JH: Pulse methylprednisolone therapy for severe alopecia areata: an open prospective study of 45 patients. J Am Acad Dermatol. 1998;39:597-602.

8. Kurosawa M, Nakagawa S, Mizuashi M, Sasaki Y, Kawamura M, Saito M. et al: A comparison of the efficacy, relapse rate and side effects among three modalities of systemic corticosteroid therapy for alopecia areata. Dermatology. 2006;212:361-5.

9. Sharma VK: Pulsed administration of corticosteroids in the treatment of alopecia areata. Int J Dermatol. 1996;35:133-6.

10. Buttgereit F, Wehling M, Burmester GR: A new hypothesis of modular glucocorticoid actions: steroid treatment of rheumatic diseases revisited. Arthritis Rheum. 1998;41:761-7.

11. Seiter S, Ugurel S, Tilgen W, Reinhold U: High-dose pulse corticosteroid therapy in the treatment of severe alopecia areata. Dermatology. 2001;202:230-4.

12. Assouly P, Reygagne P, Jouanique C, Matard B, Marechal E, Reynert $\mathrm{P}$, et al: Intravenous pulse methylprednisolone therapy for severe alopecia areata: an open study of 66 patients (in French). Ann Dermatol Venereol. 2003;130:326-30.
13. Gupta AK, Ellis CN, Cooper KD, Nickoloff BJ, Ho VC, Chan LS, et al: Oral cyclosporine for the treatment of alopecia areata: a clinical and immunohistochemical analysis. J Am Acad Dermatol. 1990;22:242-50.

14. Shapiro J, Lui H, Tron V, Ho V: Systemic cyclosporine and lowdose prednisone in the treatment of chronic severe alopecia areata: a clinical and immunopathologic evaluation. J Am Acad Dermatol. 1997;36:114-7.

15. Joly P: The use of methotrexate alone or in combination with low doses of oral corticosteroids in the treatment of alopecia totalis or universalis. J Am Acad Dermatol. 2006;55:632-6.

16. Heffernan MP, Hurley MY, Martin KS, Smith DI, Anadkat MJ: Alefacept for alopecia areata. Arch Dermatol. 2005;141:1513-6.

Copyright by Neerja Puri. This is an open access article distributed under the terms of the Creative Commons Attribution License, which permits unrestricted use, distribution, and reproduction in any medium, provided the original author and source are credited. 